Pacific Journal of Mathematic

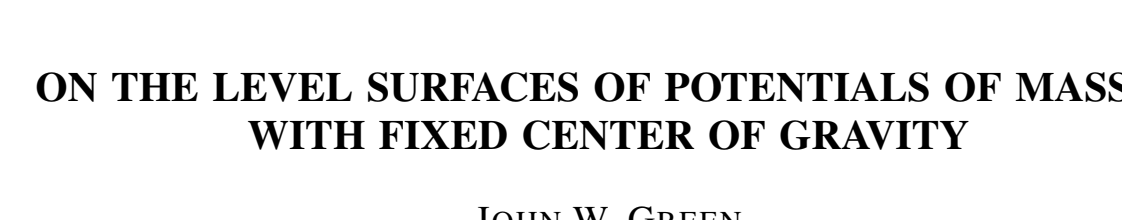




\title{
ON THE LEVEL SURFACES OF POTENTIALS OF MASSES WITH FIXED CENTER OF GRAVITY
}

\author{
JOHN W. GREEN
}

1. Introduction. Let $\mu(e)$ be a nonnegative additive set function on the closed unit sphere $K$ in three dimensions with $\mu(K)=1$. We shall regard $\mu$ as a distribution of unit positive mass on $K$. Furthermore, we shall require that the center of gravity of this distribution be at the origin; that is,

$$
\int_{K} x d \mu=\int_{K} y d \mu=\int_{K} z d \mu=0
$$

Such $\mu$ will be called admissible distributions, and their Newtonian potentials $u(P)$, admissible potentials.

In O. D. Kellogg's Foundations of Potential Theory [1], there occurs on page 144 an exercise which amounts to the following: Show that a level surface of an admissible potential which lies outside a concentric sphere of radius 10 varies in distance from the origin by less than 1.2 per cent. The figure 1.2 appears to be correct, as we shall show by an example, only when variation is interpreted to mean variation from some intermediate sphere. Then with this interpretation, Kellogg's figure is easily obtained by considering the expansion of the potential in a series of spherical harmonics, whose use the set in which this problem appears was designed to illustrate. However, since the estimates used are fairly crude, the figure is not attained by any level surface.

In this note is solved the problem of exactly how much a level surface of an admissible potential can depart from being spherical, and what distributions give the extreme level surfaces. More precisely, we shall prove the following theorem:

THEOREM 1. If a level surface of an admissible potential has minimum radius $r$ and maximum radius $R$, with $r>1$, then

$$
2 R \leq\left[\left(r^{2}+1\right)^{1 / 2}+\left(r^{2}+5\right)^{1 / 2}\right] .
$$

This value is attained if and only if the distribution consists of two equal point

Received October 30, 1951.

Pacific J. Math. 2 (1952), 147-152 
masses at the ends of a diameter of $K$.

In Kellogg's example, we have $r=10$, and for the extreme distribution given above, $R-r=.0148 r$.

2. Extremes of an admissible potential. In order to prove Theorem 1, we first prove two results concerning the maximum and minimum values of an admissible potential at a fixed distance from the origin.

THEOREM 2. The value of an admissible potential at a point $P$ at distance $a$ from the origin, $a>1$, is at most $a /\left(a^{2}-1\right)$. It equals this value if and only if the distribution consists of two equal point masses at the extremities of that diameter of $K$ which passes through $P$.

We shall give proofs which depend only on the decreasing and convex nature of the function $1 / r$. When this is done, our theorems, with appropriate changes in the given bounds, will have been proved not only for Newtonian potentials, but also for any potential based on a decreasing convex function, such as the logarithmic potential.

Let then $\phi(r)$ be a strictly decreasing, strictly convex function of $r$ for $r>0$. Potentials will be defined by

$$
u(P)=\int_{K} \phi(r) d \mu \text {. }
$$

Let $P$ be at distance $a$ from the origin and let $\mu_{0}$ be an admissible distribution maximizing the potential at $P$. That such a distribution exists is an immediate cons equence of the notion of weak convergence of mass distributions [2, p. 1092]. It may be assumed that $P$ is the point $(a, 0,0)$. It is at once apparent that $\mu_{0}$ can have no mass except on the $x$-axis, since any mass off this axis could be projected onto it without affecting the center of gravity, and at the same time be brought closer to $P$. This would increase the potential at $P$, since $\phi$ is strictly decreasing. Thus $\mu_{0}$ is a linear distribution on the $x$-axis.

Let $\nu(e)$ be any distribution of mass with center of gravity at $O$ and such that $\mu_{0}(e)+\lambda \nu(e)$ is nonnegative for small $|\lambda|$. Then $\left(\mu_{0}+\lambda \nu\right) /[1+\lambda \nu(K)]$ is an admissible distribution. If $g(\lambda)$ is the potential at $P$ of this distribution, then $g^{\prime}(0)=0$ because of the extreme nature of $\mu_{0}$. This gives, by an easy computation,

$$
u(P)=\int_{K} \phi(r) d \nu=\nu(K) u_{0}(P),
$$

where $u$ and $u_{0}$ are the potentials of $\nu$ and $\mu_{0}$ respectively. Suppose that the 
kernel of the mass $\mu_{0}$ contains three distinct points: $x_{1}, x_{2}, x_{3}$. Let $L_{i}$ be a small interval about $x_{i}$, and set

$$
\nu_{i}(e)=\mu_{0}\left(e \cdot L_{i}\right) \quad(i=1,2,3) .
$$

Let $\bar{x}_{i}$ be the center of gravity of $\nu_{i}(e)$, and $\lambda_{1}, \lambda_{2}, \lambda_{3}$ be parameters such that

$$
\sum_{i} \bar{x}_{i} \lambda_{i} \nu_{i}(K)=\sum_{i} \bar{x}_{i} \lambda_{i} \mu_{0}\left(L_{i}\right)=0 .
$$

Then $\nu(e)=\sum_{i} \lambda_{i} \nu_{i}(e)$ satisfies the conditions at the beginning of this paragraph, and so (l) is satisfied. Now by the mean value theorem,

$$
u(P)=\int_{K} \phi d \nu=\sum_{i} \lambda_{i} \int_{L_{i}} \phi d \nu_{i}=\sum_{i} \lambda_{i} \mu_{0}\left(L_{i}\right) \phi\left(a-x_{i}^{\prime}\right),
$$

where $x_{i}^{\prime} \in L_{i}$. Thus it follows that

$$
\sum_{i}\left[\lambda_{i} \mu_{0}\left(L_{i}\right)\right] \overline{x_{i}}=0
$$

implies that

$$
\sum_{i} \lambda_{i} \mu_{0}\left(L_{i}\right) \phi\left(a-x_{i}^{\prime}\right)=u_{0}(P) \sum_{i} \lambda_{i} \mu_{0}\left(L_{i}\right),
$$

or

$$
\sum_{i}\left[\lambda_{i} \mu_{0}\left(L_{i}\right)\right]\left[\phi\left(a-x_{i}^{\prime}\right)-u_{0}(P)\right]=0
$$

Hence there exists a constant $\alpha$ such that

$$
\phi\left(a-x_{i}^{\prime}\right)-u_{0}(P)=\alpha \bar{x}_{i} .
$$

If $\left|L_{i}\right| \longrightarrow 0$, then $\bar{x}_{i}$ and $x_{i}^{\prime}$ tend to $x_{i}$. Equation (2) is false in the limit, since it states that the three points $\left(x_{i}, \phi\left(a-x_{i}\right)\right), i=1,2,3$, are collinear, whereas $\phi$ is strictly convex. Hence (2) is false for small $\left|L_{i}\right|$, and $\mu_{0}$ has not three points in its kernel. 
We now see that $\mu_{0}$ consists of at most two point masses, $m_{1}$ at $x_{1}$ and $m_{2}$ at $x_{2}$, with $m_{1} x_{1}+m_{2} x_{2}=0$ and $m_{1}+m_{2}=1$. We may take $x_{1}>0, x_{2} \leq 0$. If this mass is distributed equally between the points \pm 1 , then the increase in potential at $P$ is given by

$$
\frac{1}{2}[\phi(a-1)+\phi(a+1)]-m_{1} \phi\left(a-x_{1}\right)-m_{2} \phi\left(a-x_{2}\right) .
$$

Setting

$$
\phi(a-x)=\psi(x), x_{1} /\left(x_{1}-x_{2}\right)=\lambda,-x_{2} /\left(x_{1}-x_{2}\right)=1-\lambda,
$$

and making use of the fact that $m_{1} x_{1}+m_{2} x_{2}=0$, we see that this increase is nonnegative provided

$$
\frac{1}{2}[\psi(1)+\psi(-1)] \geq \lambda \psi\left(x_{2}\right)+(1-\lambda) \psi\left(x_{1}\right) .
$$

But $\lambda x_{2}+(1-\lambda) x_{1}=0$, and we recognize the right member of (3) as the value at 0 of the linear function agreeing at $x_{1}$ and $x_{2}$ with $\psi$. The left member is the value at 0 of the linear function agreeing with $\psi$ at \pm 1 . Since $\psi$ is convex and $-1 \leq x_{2} \leq 0<x \leq 1$, the inequality (3) is obviously true, and, in view of the strict convexity of $\psi$, the inequality is strict unless $x_{2}=-1, x_{1}=1$. Thus $\mu_{0}$ can contain nothing but masses $1 / 2$ at \pm 1 , so that with $\phi(r)=1 / r$ we have

$$
u(P)=\frac{1}{2}\left[\frac{1}{a-1}+\frac{1}{a+1}\right]=\frac{a}{a^{2}-1} .
$$

For future reference note that if the masses $m_{1}$ and $m_{2}$ are moved from $x_{1}, x_{2}$ to 0 , the decrease in potential at $P$ may be written

$$
\lambda \psi\left(x_{2}\right)+(1-\lambda) \psi\left(x_{1}\right)-\psi(0) \geq 0
$$

in view of the convexity of $\psi$. The inequality sign will hold if either mass is not at zero.

THEOREM 3. The value of an admissible potential at a point $P$ at distance a from the origin, $a>1$, is at least $\left(a^{2}+1\right)^{-1 / 2}$. It equals this value if and only if the distribution lies on the equatorial great circle of $K$ (regarding $O P$ as the axis of $K)$.

Let $\mu_{0}$ be an admissible distribution minimizing the potential at $P$. If $\mu_{0}^{\prime}$ is 
the distribution obtained by averaging $\mu_{0}$ and the distribution obtained by reflecting $\mu_{0}$ in the $x$-axis, then $\mu_{0}^{\prime}$ is admissible, symmetric with respect to the $x$-axis, and minimizes the potential at $P$. Now $\mu_{0}^{\prime}$ has no mass interior to $K$ since we could move all such mass cylindrically outward from the $x$-axis on to the surface of $K$; this would leave unaltered the center of gravity and the total mass but would decrease the potential at $P$. Thus $\mu_{0}$ also has no mass interior to $K$.

Let $\nu_{0}$ be the mass distribution, on the meridian semicircle of $K$ in the $x y$ plane for which $y \geq 0$, obtained by concentrating all the mass on each set of parallels of latitude on the set of intersections of the se parallels with the semicircle. Then $\nu_{0}$ has total mass 1 , has its center of gravity on $x=0$, and gives the minimum potential at $P$. By reversing this concentration procedure it is a simple matter to construct from any $\nu_{0}$ with the three listed properties an admissible distribution with the same potential at $P$. What we must show, then, is that $\nu_{0}$ consists of a point mass at $(0,1,0)$; the method is analogous to that in the proof of Theorem 2. If

$$
\theta(x)=\phi\left(\sqrt{1+a^{2}+2 a x}\right)
$$

it follows that since $\phi$ is strictly decreasing and strictly convex, the same is true of $\theta$ [3]. Using $\theta$ instead of $\phi$, we proceed exactly as in Theorem 2, the final remark in that proof showing that only the point mass at $x=0$ gives the minimum potential.

3. Proof of Theorem 1. Let a level surface, $u=u_{0}$, of an admissible potential $u$ have minimum radius $r$ and maximum radius $R$, with $r>1$. Then from Theorems 2 and 3 we get

$$
1 / \sqrt{r^{2}+1} \leq u_{0} \leq R /\left(R^{2}-1\right)
$$

This gives

$$
R^{2}-R \sqrt{r^{2}+1}-1 \leq 0,
$$

which when solved for $R$ is precisely the inequality stated in Theorem 1. In order for the equality to hold, the distribution $\mu$ must maximize the potential at a point at distance $r$ and minimize it at a point at distance $R$. Again from Theorems 2 and 3 this is possible if and only if $\mu$ consists of a pair of equal and diametrically opposed point masses. 


\section{REFERENCES}

1. O. D. Kellogg, Foundations of Potential Theory, Berlin, 1929.

2. J. Radon, Über lineare Funktionaltransformationen und Funktionalgleichungen, Sitzungsber. Akad. Wiss. Wien. 128 (1919), 1083-1121.

3. J. L. W. V. Jensen, Sur les fonctions convexes et les inégalitiés entre les valeurs moyennes, Acta Math. 30(1906), 190.

The University of California, Los Angeles, and

The Institute for Advanced Study 


\section{PACIFIC JOURNAL OF MATHEMATICS}

\section{EDITORS}

R. M. RoBINSON

University of California Berkeley 4, California

\section{*R. P. Dilworth}

Califomia Institute of Technology Pasadena 4, California

\section{E. F. BECKENBACH, Managing Editor}

University of California

Los Angeles 24, California

*During the absence of Herbert Busemann in 1952.

\section{ASSOCIATE EDITORS}

\author{
R. P. DILWORTH \\ HERBERT FEDERER \\ MARSHALL HALL
}

\author{
P. R. HALMOS \\ HEINZ HOPF
}

R. D. JAMES

\author{
BØRGE JESSEN \\ PAUL LÉVY \\ GEORGE PÓLYA
}

\author{
J. J. STOKER \\ E. G. STRAUS
}

KÖSAKU YOSIDA

\section{SPONSORS}

UNIVERSITY OF BRITISH COLUMBIA

CALIFORNIA INSTITUTE OF TECHNOLOGY

UNIVERSITY OF CALIFORNIA, BERKELEY

UNIVERSITY OF CALIFORNIA, DAVIS

UNIVERSITY OF CALIFORNIA, LOS ANGELES

UNIVERSITY OF CALIFORNIA, SANTA BARBARA

OREGON STATE COLLEGE

UNIVERSITY OF OREGON

\author{
UNIVERSITY OF SOUTHERN CALIFORNIA \\ STANFORD UNIVERSITY \\ WASHINGTON STATE COLLEGE \\ UNIVERSITY OF WASHINGTON \\ AMERICAN MATHEMATICAL SOCIETY \\ NATIONAL BUREAU OF STANDARDS, \\ INSTITUTE FOR NUMERICAL ANALYSIS
}

Mathematical papers intended for publication in the Pacific Journal of Miathematics should be typewritten (double spaced), and the author should keep a complete copy. Manuscripts may be sent to any of the editors. All other communications to the editors should be addressed to the managing editor, E. F. Beckenbach, at the address given above.

Authors are entitled to receive 100 free reprints of their published papers and may obtain additional copies at cost.

The Pacific Journal of Mathematics is published quarterly, in March, June, September, and December, by the University of California, Berkeley 4, California. The price per volume (4 numbers) is $\$ 8.00$; single issues, $\$ 2.50$. Special price to individual faculty members of supporting institutions and to individual members of the American Mathematical Society: $\$ 4.00$ per volume; single issues, $\$ 1.25$.

Subscriptions, orders for back numbers, and changes of address should be sent to the publishers, University of California Press, Berkeley 4, California.

Printed at Ann Arbor, Michigan. Entered as second class matter at the Post Office, Berkeley, California.

\section{UNIVERSITY OF CALIFORNIA PRESS • BERKELEY AND LOS ANGELES}




\section{Pacific Journal of Mathematics}

\section{Vol. 2, No. $2 \quad$ February, 1952}

L. Carlitz, Some theorems on Bernoulli numbers of higher order...

Watson Bryan Fulks, On the boundary values of solutions of the heat equation........................................ 141

John W. Green, On the level surfaces of potentials of masses with fixed center of gravity................................... 147

Isidore Heller, Contributions to the theory of divergent series .......... 153

Melvin Henriksen, On the ideal structure of the ring of entire functions . . . 179

James Richard Jackson, Some theorems concerning absolute neighborhood retracts........................................ 185

Everett H. Larguier, Homology bases with applications to local connectedness ................................... 191

Janet McDonald, Davis's canonical pencils of lines ................ 209

J. D. Niblett, Some hypergeometric identities . . . . . . . . . . . . . . . . . . 219

Elmer Edwin Osborne, On matrices having the same characteristic equation...................................... 227

Robert Steinberg and Raymond Moos Redheffer, Analytic proof of the

Lindemann theorem ................................. 231

Edward Silverman, Set functions associated with Lebesgue area ......... 243

James G. Wendel, Left centralizers and isomorphisms of group algebras . . 251

Kosaku Yosida, On Brownian motion in a homogeneous Riemannian space. 